\title{
ANALYSIS OF SHIP BEHAVIOR UNDER INFLUENCE OF WAVES AND CURRENTS
}

\author{
A. Armudi ${ }^{\mathrm{a}}$, \\ W. C. Marques ${ }^{b}$, \\ and $\mathbf{P}$. H. Oleinik ${ }^{\mathrm{a}}$ \\ ${ }^{\text {a }}$ Universidade Federal do Rio Grande \\ Escola de Engenharia \\ Bairro Carreiros \\ Av. Itália, km 8, CP. 474, Rio Grande, RS, Brasil \\ amandaarmudi@gmail.com \\ ${ }^{\mathrm{b}}$ Universidade Federal do Rio Grande \\ Instituto de Matemática Estatística e Física \\ Bairro Carreiros \\ Av. Itália, km 8, CP. 474, Rio Grande, RS, Brasil
} Received: May 11, 2017 Revised: June 12, 2017 Accepted: July 12, 2017

\section{ABSTRACT}

The most important environmental factors related to safety of ship and performance on high sea are surface winds and waves. In order to obtain an optimal trajectory of a ship route, it is a prerequisite to know the sea state condition, as well as, the behavior of the ship in waves and currents. The purpose of this study is to analyze the ship behavior under the influence of 3 different sea state conditions over the Southern Brazilian inner shelf near the Rio Grande coastal region. SHIPMOVE and TOMAWAC + TELEMAC3D system were simulated under three different wave scenarios. Day 4 showed the shortest traveled distance and lowest velocity. The sea state of Day 33 deflected the initial vessel path northeasterly and generated high rotational motions. Day 100 depicted the longest final displacement and highest average velocity, where this event showed the most smooth sea state condition. Lastly, the ship behavior seems to be strongly influenced by the sea state condition for the three events.

Keywords: shipmove, tomawac, telemac3d, numerical model, ship motion

\section{NOMENCLATURE}

A area of the vessel perpendicular to the displacement, $\mathrm{m}^{2}$

B potential damping matrix, $\mathrm{Kg} / \mathrm{s}$

$\mathrm{C}$ polynomial function of the ship contour, $\mathrm{m}$

$\mathrm{C}_{\mathrm{A}} \quad$ aerodynamic drag coefficient

$\mathrm{C}_{\mathrm{D}}$ drag coefficient

$\mathrm{C}_{\mathrm{M}}$ inertia coefficient

$\mathrm{C}_{\mathrm{O}}$ wave drag coefficient

D transversal dimension of the body, $m$

$\mathrm{D}_{\mathrm{A}}$ friction-induced drag, $\mathrm{m}^{4} / \mathrm{s}^{2}$

$\mathrm{D}_{\mathrm{O}} \quad$ wave-induced drag, $\mathrm{m}^{4} / \mathrm{s}^{2}$

$\mathrm{F}_{\mathrm{C}} \quad$ centrifugal forces, $\mathrm{N}$

$\mathrm{F}^{\text {ext }}, \mathrm{F}_{\mathrm{e}}$ external forces applied to the system, $\mathrm{N}$

I inertia matrix, $\mathrm{Kg}$

$\mathrm{L}$ lagrangian of the coordinate system q, J

$\mathrm{M}_{\mathrm{A}} \quad$ additional mass, $\mathrm{Kg}$

q generalized coordinate system, $\mathrm{m}$

$\mathrm{R}$ rotation vector of the vessel, rad

$\mathrm{t}$ time, $\mathrm{s}$

$\mathrm{T} \quad$ kinetic energy of the system, $\mathrm{J}$

$T_{m} \quad$ thrust of the vessel's engine, $\mathrm{N}$

$u_{n} \quad$ velocity of the vessel, $\mathrm{m} / \mathrm{s}$

$\mathrm{U}$ potential energy of the system, $\mathrm{J}$

$v_{n} \quad$ velocity of the fluid, $\mathrm{m} / \mathrm{s}$

$\mathrm{w}$ length of the vessel, $\mathrm{m}$

$\mathrm{x}, \mathrm{y}, \mathrm{z}$ cartesian coordinates, $\mathrm{m}$

$\mathrm{X}$ translation vector of the vessel, $\mathrm{m}$

\section{Greek symbols}

$\begin{array}{ll}\alpha & \text { yaw, rad } \\ \beta & \text { pitch, rad } \\ \gamma & \text { roll, rad } \\ \rho & \text { specific mass of the water, } \mathrm{Kg} / \mathrm{m}^{3} \\ \sigma & \text { the six degrees of freedom, } \mathrm{m} / \mathrm{s}\end{array}$

\section{INTRODUCTION}

The evolution of shipbuilding has resulted in the development of new operating configurations for high speed ships Sclavounos (1984). The new operating configurations occurred due to the following reasons: ocean articulated convoys, phase approach of the side discharge for tankers, and supplying fuel to military vessels. These new operating conditions produce hydrodynamic interference on vessel dynamics due to radiated and diffracted waves between vessels. Therefore, it is necessary to develop numerical tools that include the effects of hydrodynamic interference on ship dynamics in order to assess the operational limits of these structures.

Over the years, many theories have been developed for vessel dynamics based on studies of ship movement under the influence of waves. The first study was conducted by Froude (1861). In his study of ship movements, Froude assumed that the large angles of movement were the result of a successive set of waves rather than a single wave. 
This author did not investigate perturbations produced by the ship on the surrounding flow.

The consideration of the flow disturbance caused by the presence of a vessel, with constant forward speed in calm waters, was developed and the advancement appeared to solve the problem of the resistance of incident waves. The first work in that direction has been attributed to Michell (1898), who was responsible for developing the Thin Ship Theory. This author assumed that the vessel draught was small compared with its length.

This consideration allowed a simplification of the problem using free surface boundary conditions and the formation of resistance due to the waves. In Michell's work, the body boundary condition was imposed only along the diametrical line of the ship. Although the numerical results obtained using the Thin Ship Theory differ significantly from experimental results, Michell's contribution was important because his theory served as a model for the simplification and solution of several problems within mathematical formulation of ship dynamics.

Haskind (1953) studied the sinking movements and pitching of vessels in waves, using Green's theorem to calculate the potential velocity associated with oscillatory movements. Haskind was the first to propose the separation of the non-permanent potential velocity into radiation contributions, diffraction and incidence of waves. However, some fundamental problems inherent in the Thin Ship Theory limited the applicability of the method. These problems include: the fact that real ships are not thin but are slender, containing draughts of the same order of magnitude as the breadth but not the length.

Michell's theory was then improved by Newman and Sclavounos (1980) and Sclavounos (1984). The unique theory of thin ships considers only the slimness of the vessel; their development placed a greater emphasis on the relationship between vessel breadth and length. By allowing a determination of ship dynamics at high and low frequencies, their theory overcame the drawbacks of the conventional thin body theory incorporating terms to account for the third dimension of the ships.

Band's Method is also used to determine the behavior of ships under the influence of waves (Moreno, 2010). The method is based on a two dimensional solution of the problem, which splits the ship into several slices (or bands) over which the hydrodynamic forces are evaluated and then integrated along the length of the ship. Thus, the dimensional problem is reduced to a succession of two dimensional problems associated with the cross sections along the length of the ship.

According to Fonseca (2004), the amplitude of the transfer functions used to define the effect that the sea state generates on the sinking movement of the ship, in the case of forward speeds, are overestimated compared with experimental results. The sea keeping performances of two model ships in regular waves was studied by Cha and Wan (2015), using their house solver model. Ship motions were accurately predicted in order to study the sea keeping performances. A comparison of the influence of different hull forms were chosen as the main task and, in this study, the heave and pitch were simulated and green water was found during the ship motion.

An application of wave model for weather routing of ships in the North Indian Ocean was developed by Padhy et al. (2008). Weather routing of ships was used to establish the shortest time route or the most economical route from a departure to arrival point by applying available information of the weather condition winds, waves and currents. Information on ship speed loss due to these effects is precomputed using sea keeping computing tools, which are then suitably employed in the optimum ship routing algorithm. The results showed that chosen algorithm is capable of finding the optimal route between a given source and destination nodes reasonably well.

In accordance with Chen et al. (2013), it is possible to achieve an optimum ship route by a numerical simulation with wind, waves and tidal currents information. Chen et al. (2013) developed a study about numerical ship navigation based on weather and ocean simulation. Numerical simulations of tidal currents, waves, and wind were applied to provide high-resolution information, which was then used to simulate ship navigation. The objective of their paper was to study how ship navigation is affected by the combined effects of sea states, such as waves, tidal currents, and wind. Simulations of two representative typhoons were conducted, and the results were compared.

The Southern Brazilian Shelf (SBS) is located between $28^{\circ}$ and $35^{\circ}$. It is continentally bounded by Rio Grande do Sul state and has a slightly rugged shoreline that is oriented Northeast-Southwest. The southwest Atlantic Ocean is one of the most dynamic regions of the global ocean (Matano et al., 2010). The coastal circulation of the SBS is dominated by northeast (NE) and southwest (SW) winds (Marques et al., 2010) and astronomical tides are less important. The spatial domain is represented by an unstructured mesh (Fig. 1) composed of 205617 nodes with varying relative distance between them from $8 \mathrm{~km}$ near the oceanic boundary to $1 \mathrm{~km}$ on the coastline. Elements with $100 \mathrm{~m}$ edge are used on the coastal region.

The most important environmental factors related to safety of ship and performance on high sea are the surface winds and waves. In order to obtain an optimal trajectory of a ship route it is a prerequisite to know the sea state condition, as well as, the behavior of the ship in waves Padhy et al. (2008). An optimum ship trajectory can be related with a safe and economic ship route, which is important to the Navy and other shipping organizations (Chen, 1978). 
Tecnologia/Technology

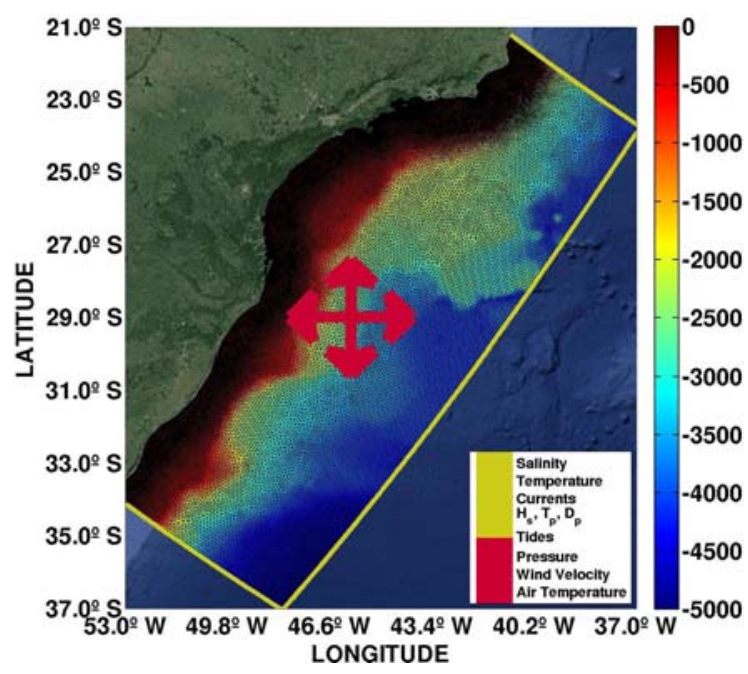

Figure 1. The South-Southeastern Brazilian Shelf and the unstructured mesh used for the spatial domain. The yellow line and the red cross indicate the position and the boundary conditions used in the TELEMAC3D and TOMAWAC models. Color bar represents the bathymetry in meters.

In this sense, the purpose of this study is to analyze the ship behavior under the influence of three distinct sea state conditions using the numerical model SHIPMOVE coupled to the wind driven waves and to the three-dimensional hydrodynamic (TOMAWAC + TELEMAC3D) system.

\section{METHODOLOGY}

\section{Telemac3D + Tomawac System}

The hydrodynamic processes were studied using the three-dimensional finite-element open-source TELEMAC3D model (www.opentelemac.org) to evaluate circulation patterns along the SBS. This model solves the Navier-Stokes equations considering the local variation of the free surface, ignoring the density variation in the mass conservation equation and considering the Boussinesq approximation to solve the momentum equations (Hervouet, 2007).

The finite element technique has been used to spatially discretize the hydrodynamic equations using sigma levels for the vertical discretization. The Multidimensional Upwind Residual Distribution (MURD) method is applied for the advection of three-dimensional variables. On the other hand, the boundary conditions in TELEMAC3D are applied according with the advective and diffusive methods used. The advection of velocities and the diffusion of velocities and tracers are solved using characteristic methods.

According to Hervouet (2007), TELEMAC3D uses this method and prescribes the boundary conditions using a radiative condition. The advection of tracers was solved using the distributive method
MURD but, in accordance with Hervouet (2007), this method ensures conservation and monotonicity. In this way, the prescription of tracers at the boundaries is applied using imposition by the Dirichlet boundary condition. Moreover, for a detailed mathematical description of the TELEMCA3D model, see Hervouet (2007).

The influence of the wind driven waves was included through the use of the sea state properties simulated by the TOMAWAC (TELEMAC-Based Operational Model Addressing Wave Action Computation), which is part of the modeling system TELEMAC. TOMAWAC simulates the changes over the time and considering a spatial domain for intra continental seas and coastal zones, using the finite elements formalism for discretization of the sea domain.

This model is a third generation wave model that computes the sea state by solving the equation of conservation of action density for the wave directional spectrum. This model represents a general situation of waves propagating in a nonhomogeneous and unsteady environment. In this way, the wave action density is preserved within the source and sink terms (TOMAWAC, 2011).

The TOMAWAC and TELEMAC3D model are directly coupled into the TELEMAC3D code. The hydrodynamic properties of the TELEMAC3D model are evaluated with a time-loop structure. Therefore, the sea state properties provided by the TOMAWAC model must be evaluated in the same structure simultaneously using a feedback coupling structure.

\section{Shipmove}

The SHIPMOVE (SHIP MOVEMENT MODEL - BR512014001163-1) model has been developed at the Universidade Federal do Rio Grande (FURG) to describe ship movement over time domain using variational theory and Lagrangian mechanics. The model considers the effect of waves and the water density field on the behavior of the vessel. It also accounts for inertial forces, damping and additional masses.

The ship can move in three directions considering six degrees of freedom. The translation of the x-axis, $y$-axis and $z$-axis are the surge, sway and heave movements, respectively. On the other hand, the rotational movements are yaw $(\alpha)$, pitch $(\beta)$ and roll $(\gamma)$ (Lewis, 1989).

$$
X^{\prime}=X+R(\alpha, \beta, \gamma)[C(t)-X]
$$

The vessel position is described by Eq. 1, where $\mathrm{X}$ represents the translation, $\mathrm{R}(\alpha, \beta, \gamma)$ is the rotation, and $C(t)$ is a polynomial function used to interpolate and parameterize the vessel contour.

$$
L(q, \dot{q}, t)=T-U
$$


In the Lagrangian mechanics formulation, each mechanical system is characterized by a defined functional that depends on a generalized coordinate system $\mathrm{q}$, its time derivative $\dot{\mathrm{q}}$ and time $\mathrm{t}$. This functional is called Lagrangian $\mathrm{L}$ of the system and is represented by $\mathrm{L}(\mathrm{q}, \dot{\mathrm{q}}, \mathrm{t})$. The Lagrangian can be written as Eq. 2, where $\mathrm{T}$ is the kinetic energy, and $\mathrm{U}$ is the potential energy of the dynamic system. The first term (on the left of Eq. 2) consists of the effects from the conservative forces.

$$
\begin{gathered}
\sum_{i}^{n} F_{i}^{e x t}=\frac{d}{d t} \frac{\partial L}{\partial \dot{q}_{i}}-\frac{\partial L}{\partial q_{i}} \\
\left(I+M_{A}\right) \ddot{\sigma}+B \dot{\sigma}+F_{C}(\alpha, \dot{\alpha})=T_{m}+F_{e}
\end{gathered}
$$

From the principle of minimum action, a system of ordinary differential equations known as EulerLagrange equations can be obtained. A system with $n$ degrees of freedom over a generalized coordinate system $\left(\mathrm{q}_{1}, \mathrm{q}_{2}, \ldots, \mathrm{q}_{\mathrm{n}}\right)$ can be written in a nonconservative form, as in Eq. 3, where $\mathrm{F}_{\mathrm{i}}^{\mathrm{ext}}$ are the external forces applied to the system. The Lagrangian of the system was first derived according to its generalized coordinates $(\mathrm{x}, \mathrm{y}, \mathrm{z})$ and temporal variations $(\dot{\mathrm{x}}, \dot{\mathrm{y}}, \dot{\mathrm{z}})$.

After the derivation, an algebraic procedure was used to organize and obtain a system of ordinary differential equations. The system of ordinary differential equations that represents the dynamics of the vessel with six degrees of freedom (x,y, $\mathrm{z}, \alpha, \beta$, $\gamma)$ is showed in Eq. 4, where I represents the inertia matrix, $\mathrm{M}_{\mathrm{A}}$ is the additional mass matrix, $\sigma$ represents the six degrees of freedom ( $\mathrm{x}, \mathrm{y}, \mathrm{z}, \alpha, \beta, \gamma), \mathrm{B}$ represents the potential damping matrix, and $F_{C}$ represents the centrifugal efforts of the system. The external forces are represented by $\mathrm{F}_{\mathrm{e}}$, and the thrust of engine is represented by the $T_{m}$ matrix.

The additional mass is the mass of fluid that moves due to the movement of the vessel. Hydrodynamic forces around a floating body are present when the body moves or rotates according to the degrees of freedom of the dynamic system. To estimate the additional mass, we assumed that the vessel is a partially submerged ellipsoid, the fluid is ideal and the forces are of a viscous nature (Korotkin, 2008).

The thrust applied was calculated based on the engine's horse power and propeller physical characteristics (Artyszuk, 2003). It was directly related with the resistance force from the vessel's displacement on the fluid at a controlled speed. The ship was initially at rest, then it assumed a respective constant thrust imposed by the ship engine $\left(10^{7} \mathrm{~N}\right)$. The engine torque was represented in the mathematical model as a thrust resulted from the ship engine.

\section{External Forces}

The external force on the ship movement is a result of wave forces, currents and ocean water density field. In order to demonstrate more realistically the ship's dynamic pattern, the effect of the fluid surrounding the vessel was added, which can be represented by the Morison equation. The Morison equation is often used to describe the effect of horizontal hydrodynamic forces generated by progressive waves on slim bodies. This equation can be decomposed into the sum of the drag and inertial forces (Avila and Adamowski, 2011).

$$
\begin{aligned}
F_{\text {ext }}=\frac{1}{2} \rho C_{D} D \mid v_{n} & -u_{n} \mid\left(v_{n}-u_{n}\right) \\
& -\rho A \dot{u}_{n} h\left(C_{M}-1\right)+\rho A \dot{v}_{n} C_{M}
\end{aligned}
$$

In this study, a variation of the Morison equation (Eq. 5) was used in which the fluid acts on an elliptical geometric structure. The equation can be decomposed into three terms. The first term represents the drag force between the ship and the water. The second term represents the acceleration and deceleration of the ship, which generates a pressure gradient (this term is known as the FroudeKrylov force). The third term refers to the inertial forces, which depend on the relative acceleration between the vessel and the water (Fish et al., 1980).

In Eq. 5, $\rho$ is the density of the fluid, $C_{D}$ is the drag coefficient, $C_{M}$ is the inertia coefficient, $D$ is the transversal dimension of the body, $\mathrm{v}_{\mathrm{n}}$ and $\dot{\mathrm{v}}_{\mathrm{n}}$ are the velocity and acceleration of the fluid, respectively, and $\mathrm{u}_{\mathrm{n}}$ and $\dot{\mathrm{u}}_{\mathrm{n}}$ are the velocity and acceleration of the vessel, respectively. The density of the fluid is calculated by the TELEMAC3D model.

\section{Drag Forces}

When an object moves in a fluid medium, there is an interaction between the body and the fluid. In turn, the object experiences a drag caused by the shear forces and pressure differences on the hull surface. Drag is a form of energy loss that acts in the opposite direction to the movement of the body. In this case, part of the ship kinetic energy is converted into thermal energy and noise.

$$
D_{A}=\frac{1}{2} U^{2} A C_{A}
$$

In this study, two different contributions for the drag forces were included. In the first case (Eq. 6), the drag is due to friction, which is the part of the drag caused by the shear tension on the hull. This drag force depends on the distribution of the tension and the form of the object. In this model, the form was approximated as a horizontally positioned and 
partially sunken cylinder.

In Eq. 6, $\mathrm{U}$ is the ship velocity, $\mathrm{A}$ is the area perpendicular to the displacement, and $\mathrm{C}_{\mathrm{A}}$ is the drag coefficient defined from the aerodynamics. According to Tupper (2004), the coefficient of a semi cylinder positioned horizontally is approximately 0.85 .

$$
D_{o}=\frac{1}{2} V^{2} w^{2} C_{o}
$$

The second contribution comes from the fact that an object loses energy by generating waves when it moves in a fluid medium. This loss of ship energy is expressed as a drag. Thus, this contribution has a greater dependence on the velocity. The wave drag produces a smaller effect on the object dynamics than the friction contribution, as shown in Eq. 7.

In Eq. 7, $\mathrm{V}$ is the wave velocity, $\mathrm{w}$ is the length of the vessel, and $C_{O}$ is the wave drag coefficient, which is affected by the Froude number (Young, 1994). Models of ship hydrostatic motion presented by Ueng (2013) were used to analyze the ship stability.

Based on the stability theory of ships and a consideration of the external forces (as the water wave influence), the damping coefficients and their contributions to the oscillation of the ship were analyzed. It was found that smaller damping coefficients resulted in longer and larger oscillations. Analogously, larger damping coefficients yielded shorter and smaller oscillations.

\section{Initial and Boundary Conditions}

The initial and boundary conditions are essential to the initialization of the numerical model. These define which vessel is going to be used in the simulation (physical characteristics of the ship) and in which environmental conditions the ship is inserted (water temperature, salinity, water density, significant wave height, velocity and acceleration of the waves).

The physical characteristics of the simulated ship are shown in Tab. 1 (www.vesselfinder.com/vessels/AMELAND-IMO9434761-MMSI-305342000). The ship started from the same Longitude $\left(51.9433^{\circ} \mathrm{W}\right)$ and Latitude $\left(32.2753^{\circ} \mathrm{S}\right)$ for the three simulations.

Table 1. Principal physical properties of the simulated ship (full scale).

\begin{tabular}{|c|c|}
\hline Length & $112 \mathrm{~m}$ \\
\hline Width & $17 \mathrm{~m}$ \\
\hline Draught & $5.7 \mathrm{~m}$ \\
\hline Gross Tonnage & $5399 \mathrm{ton}$ \\
\hline
\end{tabular}

Three wave events were chosen considering the highest significant height from an annual wind-driven waves simulation starting on January 1st, 2013. The first simulated event started on January $4^{\text {th }}$ (Day 4), the second on February $2^{\text {nd }}$ (Day 33) and the third on April $10^{\text {th }}$ (Day 100). The intensity $(\mathrm{m} / \mathrm{s})$ and direction $\left(^{\circ}\right)$ were analyzed considering a sum of wave and current parameters. The intensity $(\mathrm{m} / \mathrm{s})$, direction $\left({ }^{\circ}\right)$ and significant wave height $(\mathrm{m})$ values were depicted in Fig.2 for the three events.

Among three events, the Day 4 showed high values of wave velocities during the entire simulation, and Day 33 displayed the highest velocity data. The maximum and minimum velocities $(\mathrm{m} / \mathrm{s})$ were 6.23 and 4.87 (Day 4), 6.46 and 2.00 (Day 33), 3.60 and 2.14 (Day 100).

Day 33 presented the highest variation on wave direction $\left({ }^{\circ}\right)$ range among the three events. It depicted a minimum value of $289.68^{\circ}$ and maximum of $303.50^{\circ}$. The other two events did not display big variations. The maximum and minimum significant heights $(\mathrm{m})$ were 2.61 and 2.05 (Day 4), 2.88 and 0.88 (Day 33), 1.90 and 1.20 (Day 100).

In order to evaluate the hydrodynamics of the SBS, the oceanographic parameters from HYCOM (HYbrid Coordinate Ocean Model, (hycom.org) were used in this work as TELEMAC3D boundary conditions. These data set present moderate temporal and spatial resolution; they also have been used worldwide. Figure 1 showed the boundary conditions implemented in TELEMAC3D. The yellow line indicates the position were the boundary conditions are imposed on TELEMAC3D using: temperature, salinity, oceanic currents and astronomical tides and on TOMAWAC using: significant wave height $\left(\mathrm{H}_{\mathrm{s}}\right)$, peak period $\left(T_{\mathrm{s}}\right)$ and average direction at the peak period $\left(D_{p}\right)$. The pink arrow represents that: air pressure and temperature, besides wind velocity are imposed over the entire domain as superficial boundary condition.

The five major components of the astronomical tides (K1, M2, N2, O1 and S2) were extracted from the TPXO - Global Inverse Solution (volkov.oce.orst.edu/tides/global.html) and also interpolated to the boundary nodes of the numerical domain. The superficial boundary was forced by winds from NOAA, from the NCEP/NCAR Reanalysis Project (esrl.noaa.gov/psd/data/gridded/data.ncep.reanalysis. $\mathrm{html}$ ) with temporal resolution of $6 \mathrm{hr}$.

In addition, TOMAWAC was forced at the oceanic boundaries by the imposition of $\mathrm{H}_{\mathrm{s}}, \mathrm{T}_{\mathrm{p}}$, and $D_{p}$, obtained from the database generated by the wave forecasting model WAVEWATCHIII (ftp://polar.ncep.noaa.gov/history/waves) with temporal resolution of $3 \mathrm{hr}$. The superficial boundary of TOMAWAC model was also forced using the dataset of winds from the NCEP/NCAR Reanalysis Project. 

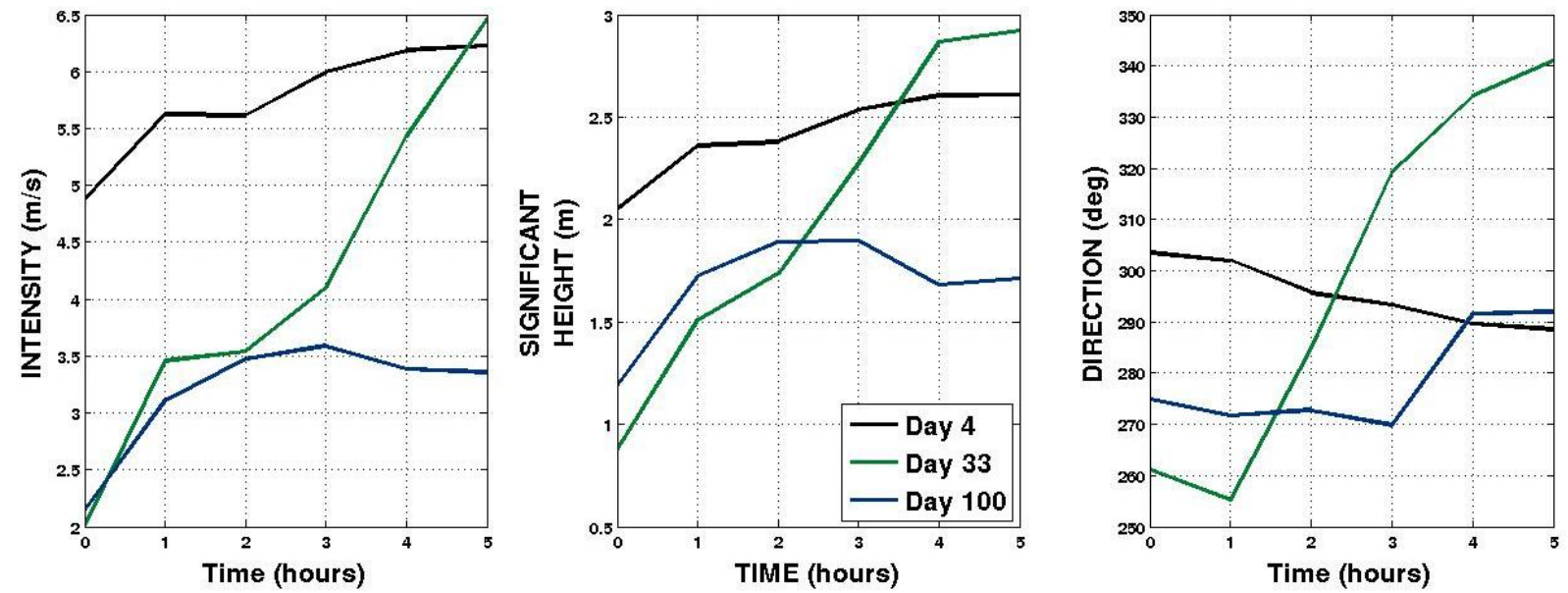

Figure 2. Wave dataset over 5 hours. (a) Wave and current velocity $(\mathrm{m} / \mathrm{s})$, (b) direction $\left(^{\circ}\right)$ and (c) significant height (m) for Day 4 (black), Day 33 (green) and Day 100 (blue).

\section{RESULTS AND DISCUSSION}

The three simulations (Day 4, Day 33 and Day 100) were performed over 5 hours, aiming to analyze

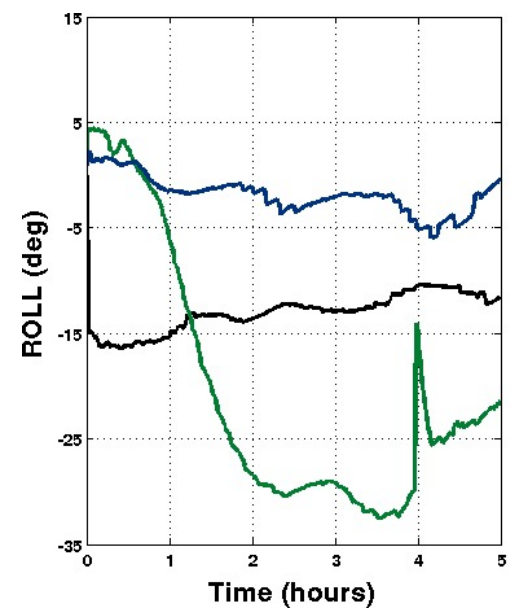

the ship behavior under wave and current actions. The angular motions (roll, pitch and yaw) for the three events were displayed in Fig. 3.

Figure 3. Ship's angular movement variation (a) roll $\left(^{\circ}\right)$, (b) pitch $\left(^{\circ}\right)$ and $(\mathrm{c})$ yaw $\left({ }^{\circ}\right)$ for Day 4 (black), Day 33 (green) and Day 100 (blue).

Within approximately $1 \mathrm{hr}$, the angular movements depicted significant disparities. Day 4 did not show a significant range of angular motion. The roll motion showed bigger values around the fifth hour of simulation, which reached an absolute angle of $16.2^{\circ}$. The pitch and yaw depicted small variations during the simulation of the Day 4. During the first hour of simulation, they had a maximum absolute angle of $7.5^{\circ}$ and $16.3^{\circ}$, respectively. The highest velocity and significant height values for Day 4 were also obtained at the end of the simulation (Fig. 2). The variations on roll and yaw can be related to the influence of strong and low variable wave conditions during this event.

The second simulation (Day 33) displayed the highest roll, pitch and yaw variations among three events. Starting from $2 \mathrm{hr}$ of simulation, the Day 33 presented three significant peaks: $32.52^{\circ}$ (roll), $14.72^{\circ}$ (pitch) and $30.20^{\circ}$ (yaw). For the same event high values of velocity, significant height and direction were displayed between the third and fourth hour (Fig. 2). So, it seems, at this time, the wave forces and large changes on wave direction were affecting the ship behavior, generating big angular motion variations.

The Day 100 depicted low variations during the simulation. The maximum absolute angles displayed were: $6.2^{\circ}$ (roll), $6.7^{\circ}$ (pitch) and $5.7^{\circ}$ (yaw). These small angular motion variations were result of low values of wave velocity and significant height. The wave direction also did not show significant variation that could influence significantly the angular movements of the vessel.

Figure 4 displayed the second and fifth hour of ship displacement for the three simulations (Day 4, Day 33 and Day 100). The wave direction $\left({ }^{\circ}\right)$ and 
significant height $(\mathrm{m})$ is shown in the same figure, being possible to identify how wave forces influence the ship behavior. The first simulation (Day 4) displayed high values of significant height and northwest wave direction during the whole simulation. This scenario provided a short ship displacement that is related with high wave forces acting constantly (Fig. 5a and Fig. 5b).

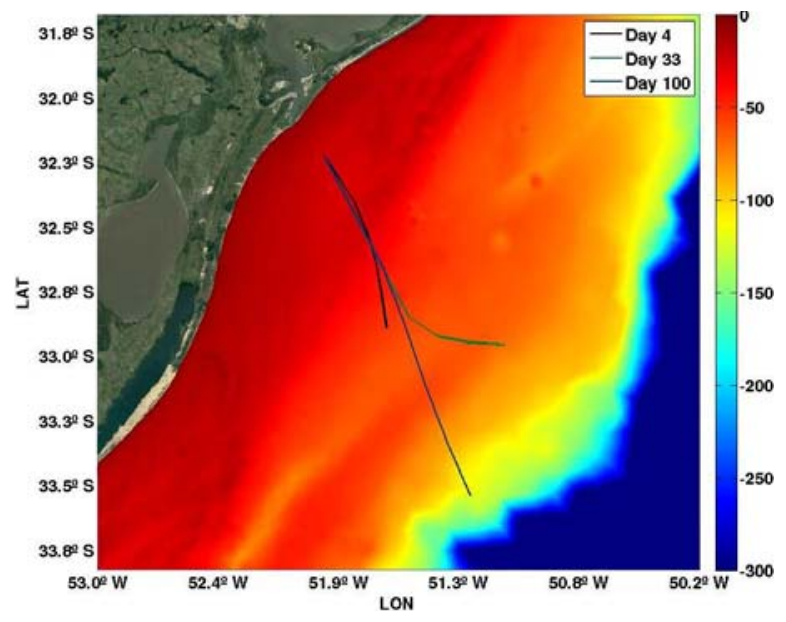

Figure 4. Ship displacement for three simulations (Day 4, Day 33 and Day 100) during 5 hours of simulation.

The significant height in the second simulation displayed lower values (Fig. 5c). Within the second hour, the vessel was able to defeat the wave forces. In the fifth hour the wave direction and significant height changed, reaching a maximum height value of $2.86 \mathrm{~m}$. Then, this new wave scenario affected the initial ship path, generating a deflection on its trajectory (Fig. 5d) and high rotational motion presented above.

On the other hand, the third simulation showed calm wave conditions. Figure $5 \mathrm{e}$ and $5 \mathrm{f}$ showed a slight changed in the initial vessel trajectory that can be related with incident waves moving it southwesterly. In order to compare the ship behavior for the three simulations, the Fig.5 displayed the vessel displacement over 5 hours of simulation.

Day 4 showed high values of wave velocity and $\mathrm{H}_{\mathrm{s}}$ during the 5 hours of simulation (Fig. 2). The wave scenario for Day 4 prompted to the shortest displacement among three events. By the end of Day 33 , the vessel displacement was deflected. It can be related with the highest values of velocity and $H_{s}$ that were displayed in the Fig. 2. Day 100 depicted the longest and more linear displacement among the simulations. The wave forces were not sufficiently high to promote a significant deflection on the ship trajectory.

Bennett et al. (2013) developed a study about the influence of forward speed on ship motions in abnormal waves. These authors presented the results of an experimental investigation into the influence of abnormal waves on a vessel traveling with forward speed in irregular seas. This study used a Leander class frigate vessel, with length of $113.40 \mathrm{~m}$, width of $12.36 \mathrm{~m}$ and draught of $4.36 \mathrm{~m}$. These results presented a maximum pitch motions (experimental results) at 18 knots in random seas, with significant heights of $3.33 \mathrm{~m}$ and $4.36 \mathrm{~m}(9.25 \mathrm{~m} / \mathrm{s})$ were $8.62^{\circ}$ and $10.50^{\circ}$, respectively. For the same ship velocity and $\mathrm{H}_{\mathrm{s}}$, the 2D linear strip theory (LST) displayed pitch motions of $\$ 6.34^{\circ}$ and $8.31^{\circ}$ and the 3D partly nonlinear sea keeping depicted (PNL) $6.57^{\circ}$ and $8.61^{\circ}$.

In the present study, each vessel showed a different average velocity 6 knots (Day 4), 11.5 knots (Day 33) and 12.8 knots (Day 100) considering the displacement after $5 \mathrm{hr}$ of simulation. The $\mathrm{H}_{\mathrm{s}}$ fluctuated between $0.87 \mathrm{~m}$ and $3 \mathrm{~m}$. For this scenario, the maximum pitch motions were $7.5^{\circ}$ (Day 4), $14.72^{\circ}$ (Day 33) and $6.7^{\circ}$ (Day 100). Even though the ship velocity for Bennett et al. (2013) analysis is greater, the pitch angles depicted similar results for the LST, PNL and the present study.

Chen et al. (2013) found an effectively estimation of ship position by comparing the results from the two typhoons cases. These authors used a ship with length of $175 \mathrm{~m}$, width of $25.40 \mathrm{~m}$ and draught of $9.50 \mathrm{~m}$ and the numerical simulation of waves was carried out using the SWAN model. The maximum calculated $\mathrm{H}_{\mathrm{s}}$ was $4 \mathrm{~m}$ and $1.4 \mathrm{~m}$ for number 1 and 2 typhoon, respectively.

According to Chen et al. (2013), the strong south winds of number 1 typhoon had an effective influence on moving the ship northward, while the ship tended to move southward in the number 2 typhoon. In the cases of navigating in inclined following waves, the ship had a tendency to move a longer than the normal distance. However, when the vessel moved in a headwind, it could make the real distance shorter. Additionally, when ship movement is influenced by lateral wave, the lateral displacements are relatively large.

Similar results were found in the present study. It showed how the intensity and direction of current and wave forces affected the ship displacement. The Figure $5 \mathrm{~b}$ displayed the shortest travel distance and Figure $5 \mathrm{~d}$ depicted lateral deflections on the initial vessel path. Both scenarios can be related with high intensity values, and a big range in the wave and current direction. In other words, the ship was not able to defeat the wave and current forces.

\section{CONCLUSIONS}

SHIPMOVE and the TOMAWAC + TELEMAC3D system were simulated under three different wave scenarios (Day 4, Day 33 and Day $100)$. The three ships started from the same Longitude $\left(51.9433^{\circ} \mathrm{W}\right)$ and Latitude $\left(32.2753^{\circ} \mathrm{S}\right)$ positions considering the same thrust. However, they did not show the same path and travel distance, once the sea state and the wave field scenarios were collected at different days for each simulation. 


\section{Tecnologia/Technology}

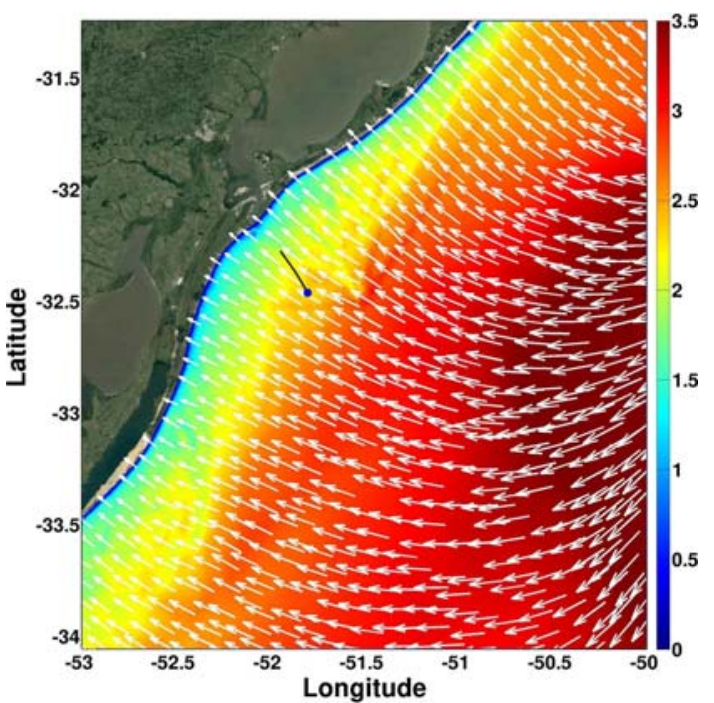

(a)

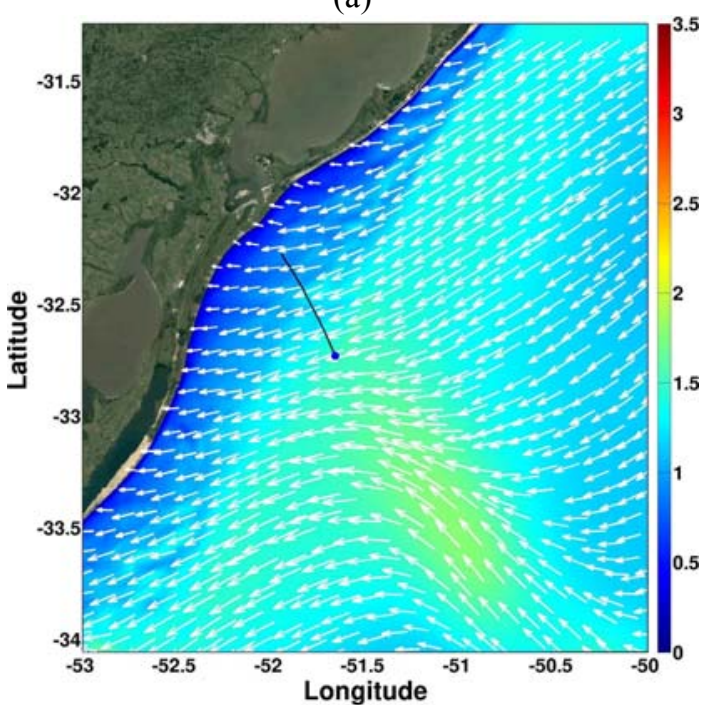

(c)

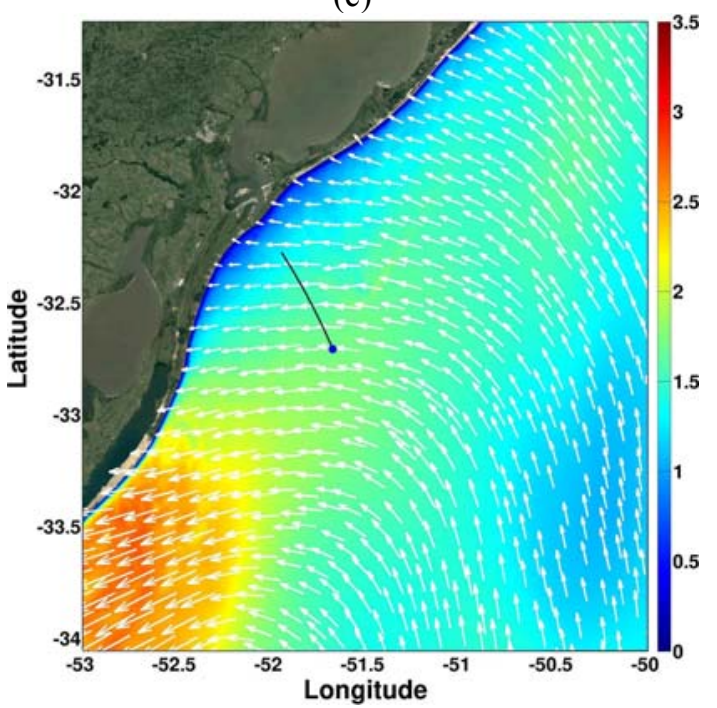

(e)
Armudi, et al. Analysis of Ship Behavior under Influence...

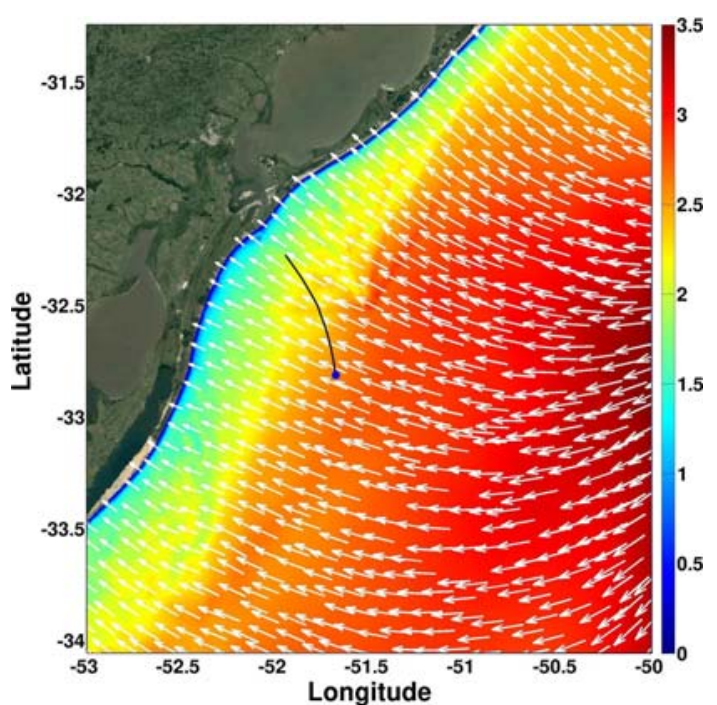

(b)

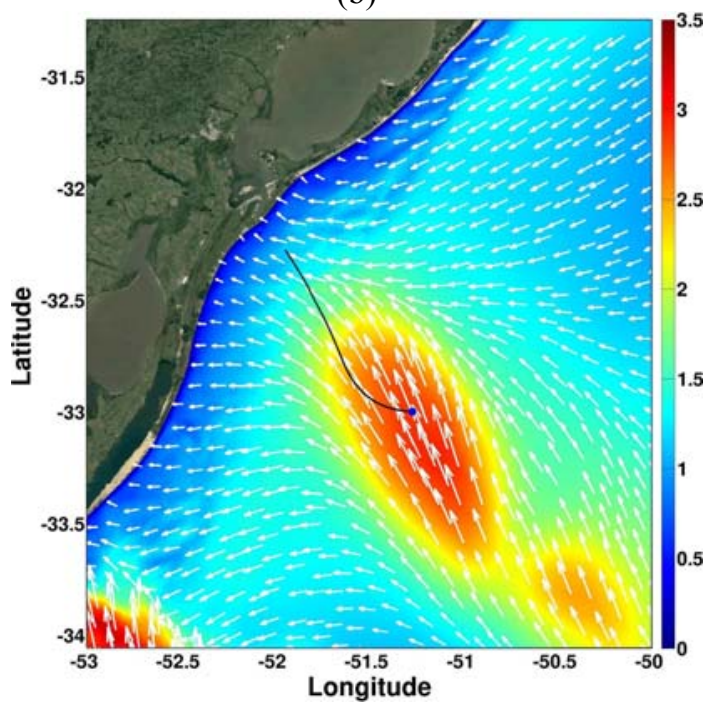

(d)

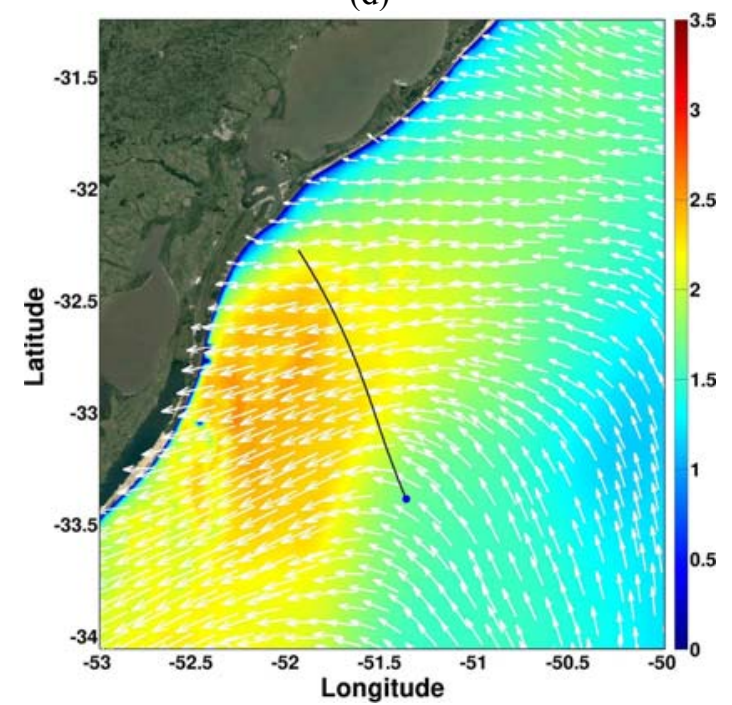

(f)

Figure 5. Ship displacement (black line), wave significant height (colors) and wave direction (white vectors) for the (a) second and (b) fifth hour of Day 4, (c) second and (d) fifth hour of Day 33 and (e) second and (f) fifth hour of Day 100. 
The wave velocity and significant wave height displayed high values during the entire simulation for Day 4. This wave field promoted the shortest ship displacement among three events. Day 33 depicted the highest significant height and the most significant range in wave direction at the ending of simulation, which was promoted by a localized sea state perturbation. This sea state condition deflected the initial vessel path northeasterly and generated high rotational motions. Day 100 reproduced the calmest wave field which was not able to prompt significant influence on ship behavior.

The travel distance for each event was $56 \mathrm{~km}$ (Day 4), $106.17 \mathrm{~km}$ (Day 33) and $118.26 \mathrm{~km}$ (Day 100). The average velocity for each vessel was 6 knots (Day 4), 11.5 knots (Day 33) and 12.8 knots (Day 100). As expected, Day 4 showed the shortest traveled distance and lowest velocity. Day 4 results were related to the fact that the vessel engine was not able to defeat the wave field properly. Day 100 depicted the longest final displacement and highest average velocity, where this event showed the most smooth sea state condition. Lastly, the ship behavior seems to be strongly influenced by the sea state condition.

\section{REFERENCES}

Artyszuk, J., 2003, Wave Fraction and thrust Deduction During Ship Astern Manoeuvres, Marine Technology, Vol. 68, No. 5.

Avila, J. P. J., and Adamowski, J. C., 2011, Experimental Evaluation of the Hydrodynamic Coefficients of a ROV through Morison's Equation, Ocean Engineering, Vol. 38, No. 17-18, pp. 21622170.

Bennett, S. S., Hudson, D. A., and Temarel, P., 2013, The Influence of Forward Speed on Ship Motions in Abnormal Waves: Experimental Measurements and Numerical Predictions, Journal of Fluids and Structures, Vol 39, pp. 154-172.

Cha, R., and Wan, D., 2015, Numerical Investigation of Motion Response of Two Model Ships in Regular Waves, Procedia Engineering, Vol. 116, No. 1, pp. 20-31.

Chen, C., Shiotani, S., and Sasa, K., 2013, Numerical Ship Navigation Based on Weather and Ocean Simulation, Ocean Engineering, Vol. 69, No. 1, pp. 44-53.

Chen, H. H. T., 1978, A Dynamic Program for Minimum Cost Ship Routing under Uncertainty, Doctoral Thesis, Massachusetts Institute of Technology, Cambridge, MA.

Fish, P., Dean, R., and Heaf, N., 1980, FluidStructure Interaction in Morison's Equation for the Design of Offshore Structures, Engineering Structures, Vol. 2, No. 1, pp. 15-26.

Fonseca, N., 2004, Comportamento do Navio no Mar, Masters Thesis, Universidade de Lisboa, Lisbon, Portugal. (in Portuguese)
Froude, W., 1861, On the Rolling of Ships, The Royal Institution of Naval Architects, Vol. 2, pp. 4064.

Haskind, M. D., 1953, The Hydrodynamic Theory of ship Oscillations in Rolling and Pitching, Society Naval Architects Marine Engineers, Vol. 10.

Hervouet, J. M., 2007, Free Surface Flows: Modelling with the Finite Element Methods, John Wiley \& Sons.

Korotkin, A. I., 2008, Added Masses of Ship Structures, Springer.

Lewis, E. V., 1989, Principles of Naval Architecture Volume III: Motions in Waves and Controllability, Society of Naval Architects and Marine Engineers, Jersey City, NJ.

Marques, W. C., Fernandes, E. H. L., and Moller, O. O., 2010, Straining and Advection Contributions to the Mixing Process of the Patos Lagoon Coastal Plume, Brazil, Journal of Geophysical Research, Vol. 115, No. C6, pp. 21562202.

Matano, R. P., Palma, E. D., and Piola, A. R., 2010, The Influence of the Brazil and Malvinas Currents on the Southwestern Atlantic Shelf Circulation, Ocean Science, Vol. 6, No. 4, pp. 983995.

Michell, J. H., 1898, The Wave-Resistence of a Ship, Philosophical Magazine, Vol. 45, No. 5, pp. 106-123.

Moreno, C. A. S., 2010, Interferência Hidrodinâmica no Comportamento em Ondas entre Navios com Velocidade de Avanço, Doctoral Thesis, Universidade Federal do Rio de Janeiro, Rio de Janeiro, Brazil. (in Portuguese)

Newman, J. N. and Sclavounos, P. D., 1980, The Unified Theory for Ship Motions, in: 13th Symposium Naval Hydrodynamics, Tokyo, Japan.

Padhy, C. P., Sen, D, and Bhaskaran, P. K., 2008, Application of Wave Model for Weather Routing of Ships in the North Indian Ocean, Natural Hazards, Vol. 44, No. 3, pp. 373-385.

Sclavounos, P. D., 1984, On the Diffraction of Free Surface Waves by a Slender Ship, Journal of Ship Research, Vol. 28, No. 1, pp. 29-47.

TOMAWAC, 2011, TOMAWAC Technical Report - Software for Sea State Modelling on Unstructured Grids over Oceans and Coastal Seas, Release 6.3, EDF R\&D.

Tupper, E. C., 2004, Introduction to Naval Architecture, $4^{\text {th }}$ edition, Elsevier.

Ueng, S. K., 2013, Physical Models for Simulating Ship Stability and Hydrostatic Motions, Journal of Marine Science and Technology, Vol. 21, No. 6, pp. 674-685.

Young, I. R., 1994, Wind Generated Ocean Waves, Volume 2, Elsevier. 